\title{
Study on Dust Production Process and Removal Equipment of Spray Drying System in Ceramic Industry
}

\author{
Z.C. HUANG, N.X. WU \& X.Q. CHENG \\ College of Mechanical and Electronic Engineering, Jingdezhen Ceramic Institute, Jingdezhen, China
}

\begin{abstract}
The producing dust process of spray drying system in ceramic industry is analyzed by experimental test. Four kinds of spray drying towers with different fuels are tested to determine the dust source. A type of dust removal and desulphurization equipment is developed for the spray drying tower of ceramic industry. It adopts a double cylinder structure with self- clean system. The test results show that the dust removal and desulphurization equipment has very high efficiency. The practice has proved that this equipment can keep the ability of dust removal for a long time and has the advantages of low cost, simple maintenance and so forth.
\end{abstract}

KEYWORD: Ceramic industry; Spray drying; Dedusting

\section{INTROUDUCTION}

Spray drying is one of the most common methods for the manufacture of a wide variety of particulate products. It is widely used in the chemical, food, household care products, pharmaceutical and ceramics industries [1-3]. In the building ceramics industry, spray drying transforms the slurry containing solids into dry particles using a hot gas. Spray drying is carried out in a tower called spray drying tower, in which the slurry is sprayed into small droplets using nozzles. The droplets come in contact with a co-current or counter-current hot gas flow and simultaneously exchange heat, mass and momentum, resulting in the solid particle formation in a single unit called powder material [4].

The spray drying production process produces a lot of dust which will seriously pollute the environment. Therefore, it is necessary to study the producing dust process of spray drying system in ceramic industry and develop the dust removal and desulphurization equipment.

\section{THE DUST SOURCE OF THE SPRAY DRYING SYSTEM}

\subsection{The technological process of spray drying system}

Fig.1 shows the technological process of spray drying system. Air is fed into the hot stove to be heated to about $1100^{\circ} \mathrm{C}$. Then the hot air is mixed and filtered in the air filter to be controlled about $620^{\circ} \mathrm{C}$. The $620^{\circ} \mathrm{C}$ hot air evenly comes into the spray drying tower, in which the slurry is sprayed into small droplets using nozzles. The droplets contact with the hot gas flow and the water in the droplets is evaporated and simultaneously the solid particles fall from the bottom of the tower. The dusty gas comes into the cyclone separator for further separating the solid component. Then the exhaust gas is introduced into the dust removal and desulfurization equipment by the fan for processing. Finally, the clean gas is discharged into the environment.

\subsection{Dust testing}

There are two dust sources in the spray drying system. One is the hot stove, and the other is the spray drying tower. The spray drying system has three dust pollution points: the discharge openings of the spray drying tower, the cyclone separator and the spray drying system. The discharge openings of the spray drying tower and the cyclone separator are in pressure equilibrium state where only leaks outside a small amount of dust-containing exhaust gas. Therefore, the spray drying system emissions are the major source of environmental pollution. In order to find out the dusting source of the spray drying system, the gas stream dust content of the inlet and discharge port of the precipitators and the hot stove with different fuels are tested. The test data of the hot stove, the spray drying tower and the cyclone separator are collected from the test point A, B and $\mathrm{C}$, respectively. Each object takes three sets of data. The results are shown in table 1 . 


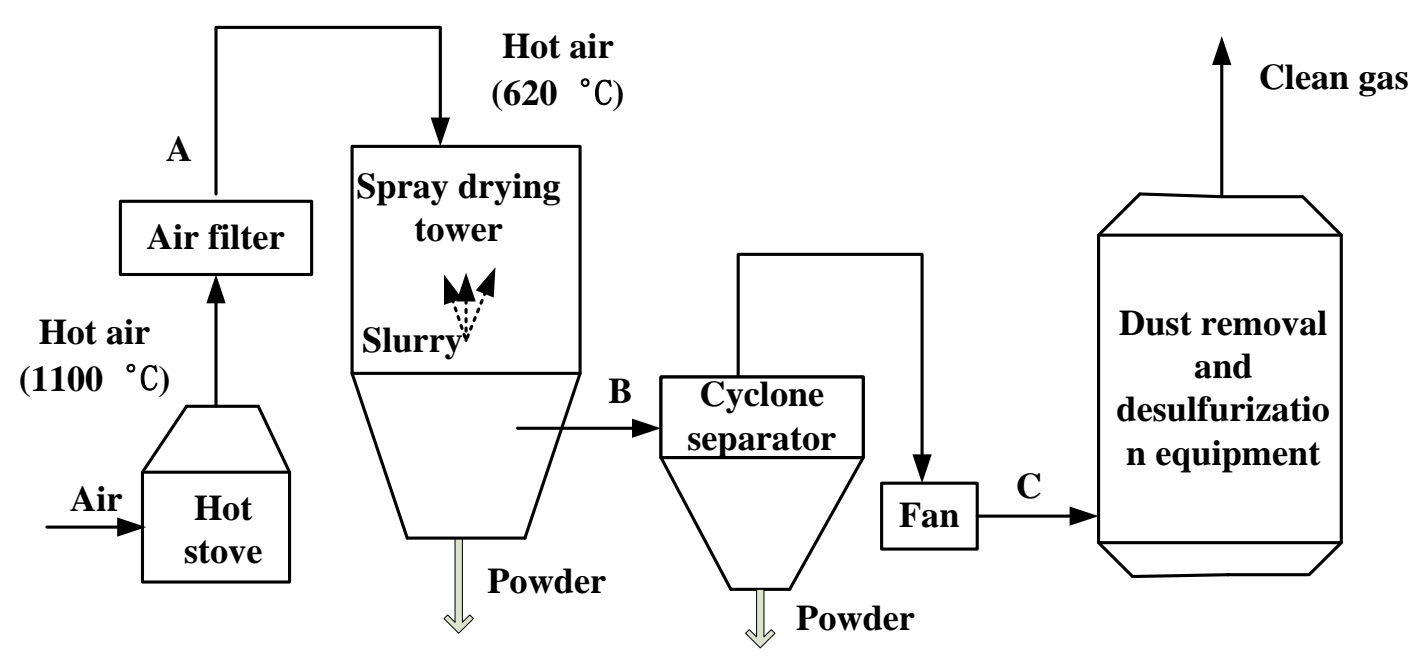

Fig.1 Flow chart for spray drying system

Table 1. The gas stream dust content of the Ceramic Industrial spray drying systems

\begin{tabular}{|c|c|c|c|c|}
\hline \multirow{2}{*}{ Tower type } & \multirow{2}{*}{ Fuel type } & \multicolumn{3}{|c|}{ Measured dust concentrations $\left(\mathrm{mg} / \mathrm{m}^{3}\right)$} \\
\hline & & Outlet of the hot stove & Exhaust gas of the spray drying tower & Exhaust gas of the cyclone separator \\
\hline \multirow{6}{*}{5000 type } & \multirow{3}{*}{ Water gas } & 1.1 & 19171.8 & 666.8 \\
\hline & & 0.5 & 18111.7 & 548.6 \\
\hline & & 0.8 & 23222.6 & 579.7 \\
\hline & \multirow{3}{*}{ Natural gas } & 0.1 & 10511.3 & 608.8 \\
\hline & & 0.2 & 9288.0 & 604.5 \\
\hline & & 0.2 & 11664.3 & 490.2 \\
\hline \multirow{6}{*}{6000 type } & \multirow{3}{*}{ Water gas } & 4.6 & 12059.7 & 546.6 \\
\hline & & 4.4 & 11665.0 & 550.2 \\
\hline & & 4.9 & 11636.1 & 482.6 \\
\hline & \multirow{3}{*}{$\begin{array}{c}\text { Coal water } \\
\text { slurry }\end{array}$} & 5.3 & 2728.5 & 99.4 \\
\hline & & 5.0 & 2122.4 & 97.5 \\
\hline & & 4.1 & 3046.1 & 71.5 \\
\hline
\end{tabular}

\subsection{Analysis of test results}

It can be seen from Table 1 that the dust content of the hot air is small and its dust contribution rate is negligible. The hot stove is the dust provider of the hot air. The measured values of the dust content in the hot air are all less than $10 \mathrm{mg} / \mathrm{m} 3$. Thus, regardless of different fuels, the hot air provided by the stove is meet emission standards. Therefore, the dust contribution rate of stove is negligible.

Spray drying tower is absolutely the dust production source of the entire system. In the spray drying tower, the slurry droplets are dried by the hot air to form powder. The dust content of the exhaust gas is very high. All of the measured average values are more than five digits. The ratios of the dust content of the exhaust gas and the hot air are all over a thousand times. Therefore, the spray drying tower is near-absolute dust production source of the entire system.
Even after the treatment of the cyclone separator, the dust content of the exhaust gas is still very high. Therefore, it is necessary to develop efficient dust removal equipment.

\section{THE DUST REMOVAL AND DESULFURATION EQUIPMENT}

\subsection{Granite water film deduster}

Granite water film deduster is a centrifugal water film deduster which is currently the most widely used dust removal device based on the theory of using water film dusting. Fig. 2 shows a type of granite water film deduster widely used in boiler flue gas dusting. The water seal and sink are provided in its bottom and top. Clean water flows into the sink from the ring shape distribution pipes, and then inflows the inner wall from the annular gap in the bottom of the tank to form a uniform film of water surrounding the inner wall. The flue gas enters the 
chimney alone tangential direction from the bottom, rises with rotating along the inner wall. Under the effect of centrifugal force, the flue gas contacts with the water film and at the same time the dust in the gas are stuck by the water film, and then flows through the bottom with the water, at last they are discharged into the ditch through the water seal.

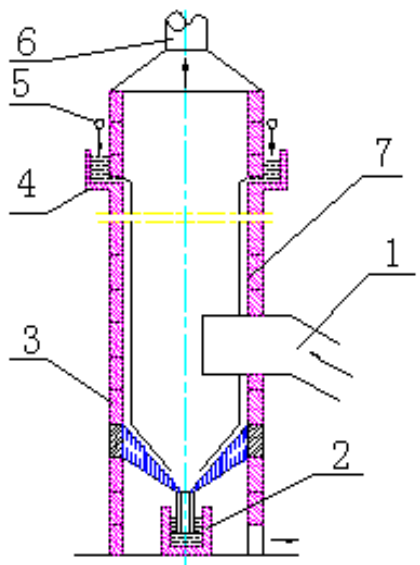

1. Flue gas inlet, 2. Water seal, 3. Granite cylindrical body, 4 . Sink, 5. Pipe, 6. Outlet 7. Water film

Fig.2 Schematic diagram of Granite water film deduster

The granite water film deduster is widely used in boiler dust removal. However, it is not suitable for the spray drying system of the ceramic industry duo to its low efficiency. Therefore, it needs to be improved.

\subsection{Introduce of the improved dust removal device}

A type of dust removal device is developed based on the above water film dedusting idea. Fig.3 shows its structure. It uses the main structure and water film dedusting idea of the granite water film deduster, but makes a number of improvements. The tower body material adopts stainless steel instead of granite to reduce weight. An inner cylinder is provided in the tower to increase the contact time of the air flow and water film. The settings of the Venturi tube, the swirler and the gas-liquid separator increas the number of the dusting. In addition, it has selfcleaning device. The lye can be injected into the lye entrance to carry out desulfurization operation.

The dust removal and desulfuration equipment has some good characteristics. Its dusting efficiency is higher than the traditional dusting device with wet methods. The fundamental idea of the Wet dusting theory is letting the dusty gas contact with water, and relying on water to capture dust particles in the dusty gas. So the dusty gas in contact with water more fully, the better the effect dusting. The equipment we developed has seven grades dusting, in other words: the gas contact with water seven times, so compared to the traditional two ways and two grades dusting, it extends the dusting time, and thus higher efficiency. It perfectly solved the problem of gas with water.
Traditional dusting device with wet methods has a very difficult problem is gas with water. If the dusting device's gas containing water, It will cause induced draft fan fouling producing vibratory and resulting in an accident. To solve this problem, we have designed a gas-liquid separator, and its structure is shown in Figure 3. before the purified gas go through induced draft fan, it will go through the gas-liquid separator to Intercept the liquid contained in the air, so the gas passed the induced draft fan will not contain the water, and it help extend the life of the induced draft fan. The device has self-cleaning ability. Inside the device, pipeline is set up carefully for self-cleaning, and it is very convenient. The bag filter and traditional dusting device with wet method have not self-cleaning ability.

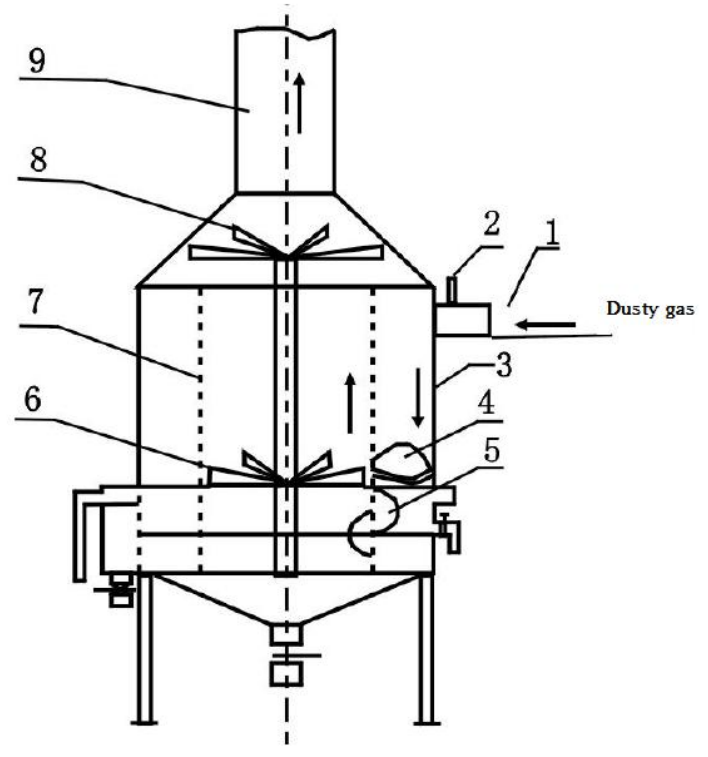

1. The Venturi tube; 2. Entrance of desulphurization lye; 3.Outer barrel; 4. Swirler; 5. s-shaped channel; 6,8. gas-liquid separator; 7. inner barrel; 9. Outlet

Fig.3 Dust removal and desulphurization equipment

\subsection{Use effect}

The device has been applied in a ceramics factory, and in its normal work process, we conducted a comprehensive Testing on the value of its import and export by using smoke tester, and the resulting data are listed in Table 2.

It can be seen from Table 1 that the emission concentration of the dust is $113.95 \mathrm{mg} / \mathrm{m}^{3}$. It is far less than the provisions of "industrial furnace air pollutant emission standards" issued by the National Environmental Protection Agency. In the provisions, the emission standard of the first category area (special protection areas) is $100 \mathrm{mg} / \mathrm{m}^{3}$, the second category area (mainly urban residential areas, etc.) is $250 \mathrm{mg} / \mathrm{m} 3$, and the third category area (Designated industrial area) is $350 \mathrm{mg} / \mathrm{m}^{3}$. The sulfur dioxide emission concentration is $25 \mathrm{mg} / \mathrm{m}^{3}$, and it is far less than the emission standard $850-1200 \mathrm{mg} / \mathrm{m}^{3}$ [5-6]. 
Table 2 Dust removal and desulphurization device monitoring data sheet

\begin{tabular}{|c|c|c|c|c|c|}
\hline Monitoring Project & $\begin{array}{c}\text { Before } \\
\text { processing }\end{array}$ & $\begin{array}{c}\text { After } \\
\text { processing }\end{array}$ & $\begin{array}{l}\text { Processing } \\
\text { efficiency }\end{array}$ & $\begin{array}{l}\text { Implementation of } \\
\text { standards }\end{array}$ & $\begin{array}{c}\text { Design } \\
\text { standards }\end{array}$ \\
\hline Dust emission concentration $\left(\mathrm{mg} / \mathrm{m}^{3}\right)$ & 3046.09 & 113.95 & 96.23 & 350 & 200 \\
\hline Dust emission rate $(\mathrm{kg} / \mathrm{h})$ & 97.69 & 4.55 & 95.34 & -------- & ----- \\
\hline $\mathrm{SO}_{2}$ emission concentration $\left(\mathrm{mg} / \mathrm{m}^{3}\right)$ & 149 & 25 & 83.22 & 850 & 200 \\
\hline $\mathrm{SO}_{2}$ emission rate $(\mathrm{kg} / \mathrm{h})$ & 4.79 & 1 & 79.1 & ----- & ------- \\
\hline Moisture content $(\%)$ & 11.18 & 6.53 & ------ & --- & ----- \\
\hline Flue gas temperature $\left({ }^{\circ} \mathrm{C}\right)$ & 92 & 64 & ------ & ---- & ----- \\
\hline Flue gas flow rate $(\mathrm{m} / \mathrm{s})$ & 10.18 & 8.31 & ------- & ----- & ----- \\
\hline
\end{tabular}

\section{CONCLUSIONS}

The producing dust process of spray drying system in ceramic industry is analyzed by experimental test. A type of dust removal and desulfuration equipment is development based on the granite water film deduster. The actual operating results show that the equipment fully meets the design requirements and has high dust removal and desulphurization efficiency. In addition, it perfectly solved the problem of gas with water, and improves the life of fan.

\section{REFERENCES}

[1] A. Muzammil et al. A one-dimensional plug-flow model of a counter-current spray drying tower. Chemical
Engineering Research and Design. 92 (2014), 826-841.

[2] K. Masters, Spray Drying: An Introduction to Principles, Operational Practice and Applications, Leonard Hill, London, 1972.

[3] H. W. Qiu et al., Investigation of the crystallization of RDX during spray drying. Powder Technology 274 (2015) 333-337.

[4] J. C. Lin, J. W. Gentry. Spray drying drop morphology: experimental study. Aerosol Sci. Technol. 37(2003), 1532.

[5] Z. C. Huang. Study on the dust removal and desulfuration equipment with wet method for ceramic industrial spray drying tower. Advanced Materials Research Vols. 347-353 (2012) pp 1272-1275.

[6] Z. C. Huang. A new wet-type dust removal and desulfuration equipment and its application in the ceramic industries. Advanced Materials Research Vols. 450-451 (2012) pp 1629-1632. 